\title{
Sequência de ensino e aprendizagem sobre radioatividade pautada na perspectiva Ciência-Tecnologia-Sociedade (CTS)
}

\author{
Teaching and learning sequence on radioactivity based on the Science-Technology- \\ Society (STS) perspective
}

\author{
Maria Daiane da Silva Monteiro \\ Mestrado em Ensino das Ciências \\ Universidade Federal Rural de Pernambuco - UFRPE. \\ Recife, Pernambuco - Brasil. \\ dayanemonteiro08@gmail.com \\ Suely Alves da Silva \\ Pós-Doutorado em Educação \\ Universidade Federal Rural de Pernambuco - UFRPE. \\ Recife, Pernambuco - Brasil. \\ suelyalvesh@gmail.com
}

Resumo: O presente artigo trata de um recorte da dissertação de uma das autoras que teve por objetivo elaborar uma Sequência de Ensino e Aprendizagem (SEA), pautada na perspectiva Ciência-Tecnologia-Sociedade (CTS), no estudo do conteúdo de Radioatividade, tendo por tema estruturador "radioatividade: riscos e benefícios". Apresentamos aqui a SEA elaborada, com base nas ideias de Méheut (2005) e Méheut e Psillos (2004), e para análise dos dados, utilizamos a análise de conteúdo de Bardin (2016), a qual evidencia que a introdução de estratégias didáticas nas quais a contextualização dos conteúdos químicos transcende exemplos cotidianos e estende a visão de mundo dos estudantes para as grandes questões sociais que os rodeiam, são fundamentais. Principalmente, na abordagem de conteúdos que apresentam abstração e dualidade, como a radioatividade. Portanto, este trabalho busca contribuir com propostas de ensino que envolvam aspectos inter-relacionados com a tríade CTS e na promoção de uma aprendizagem crítica dos estudantes.

Palavras-chave: Perspectiva CTS. Radioatividade. Sequência de ensino e aprendizagem.

\begin{abstract}
This article deals with an excerpt from the dissertation of one of the authors and objective was to develop a Teaching and Learning Sequence (TLS), based on the ScienceTechnology-Society (STS) perspective, in the study of the content of Radioactivity, having as its structuring theme "radioactivity: risks and benefits". We present here the TLS elaborated, based on the ideas proposed by Méheut (2005) and Méheut and Psillos (2004), and for data analysis, we used the content analysis proposed by Bardin (2016), which shows that the introduction of didactics in which the contextualization of chemical contents transcends everyday examples and extends the students' worldview to the great social issues that surround them, are fundamental. Mainly, in the content approach that presents abstraction and duality, such as radioactivity. Therefore, this work seeks to contribute to teaching proposals that involve aspects interrelated with the STS triad and in promoting critical student learning.
\end{abstract}

Keywords: STS Perspective. Radioactivity. Teaching and learning sequence. 


\section{Introdução}

O ensino pautado na transmissão de informações tem sido questionado de longas datas. Entretanto, ainda é comum, no processo de ensino e aprendizagem, encontrarmos traços marcantes do modelo tradicional de ensino, voltado à abordagem de conceitos de forma fragmentada, valorizando apenas o conteúdo. Diversas são as pesquisas que evidenciam o ensino de química como tradicional, por esse se mostrar tão pautado na realização mecânica de cálculos e na memorização e repetição de equações químicas, nomes e fórmulas, tornando o conhecimento científico distante do cotidiano dos estudantes (SCHNETZLER, 2002; OLIVEIRA, 2004).

Com o intuito de alterar esse quadro, o ensino das ciências naturais, em particular, o ensino de química, vem passando por reformulações, principalmente no que diz respeito às metodologias adotadas pelos docentes. Segundo os documentos oficiais que norteiam a educação brasileira, como a Lei de Diretrizes e Bases da Educação Nacional - LDB n ${ }^{\circ}$ 9.394/96, os Parâmetros Curriculares Nacionais - PCN (BRASIL, 1999) e a Base Nacional Comum Curricular - BNCC (BRASIL, 2018), o ensino de química deve possibilitar aos estudantes o desenvolvimento do senso crítico, para o pleno exercício da cidadania e não reduzir-se a mera reprodução de informações.

Pensando nisso, propostas de ensino mais progressistas que buscam a produção do conhecimento e a formação de cidadãos críticos vêm sendo discutidas nas pesquisas da área, justificadas pelo atendimento às necessidades emergentes do contexto sócio-histórico atual. Dentre outras, destacamos a perspectiva de ensino em Ciência, Tecnologia e Sociedade - CTS que, desde a década de setenta, incorpora aos currículos de ensino de ciências, questões relacionadas com a ciência, a tecnologia e os aspectos socioambientais (SANTOS; SCHNETZLER, 2010).

Assim sendo, este trabalho visa destacar a importância de se introduzir nas salas de aula abordagens que evidenciem a relevância social do conhecimento científico e contribuam para o desenvolvimento nos estudantes da capacidade de tomada de decisão. Deste modo, assume por objetivo elaborar uma Sequência de Ensino e Aprendizagem (SEA), pautada na perspectiva CTS, no estudo do conteúdo de Radioatividade, tendo por tema estruturador "radioatividade: riscos e benefícios".

\section{A perspectiva cts no ensino de química}

Desde meados do século XX, nos países capitalistas centrais, foi crescendo o sentimento de que o desenvolvimento científico, tecnológico e econômico não estava ascendendo paralelamente ao bem-estar social e, portanto, havia-se uma necessidade do cidadão reconhecer seus direitos, pensar por si próprio e ter uma visão crítica da sociedade onde vive, de modo a 
interferir sobre ela (VAZ; FAGUNDES; PINHEIRO, 2009). Entretanto, somente no final da década de 60, após uma euforia inicial com os resultados dos avanços científico e tecnológico, é que a ciência e a tecnologia (CT) se tornam alvo de um olhar mais analítico. $\mathrm{Na}$ tentativa de compreender a ciência e a tecnologia em seu contexto histórico, social e cultural, emerge o movimento Ciência-Tecnologia-Sociedade - CTS: tradição Europeia (Science and Technology Studies STS) e Norte-Americana (Science Technology and Society - STS) (PINHEIRO, 2005).

Apesar de não se dirigir diretamente para o âmbito educacional, o movimento CTS se revelou como uma alternativa para o ensino de ciências, pois uma das direções do movimento estava voltada para uma educação científica e tecnológica, tendo como finalidade, a obtenção de conhecimentos científicos, que levem os estudantes a atuarem como sujeitos críticos e reflexivos na sociedade atual. Neste sentido, o movimento sugeriu uma mudança de postura na educação, na estrutura curricular dos conteúdos, em que o estudante sai da posição de espectador, e assume uma postura de ser pensante, que procura estar envolvido nas questões e decisões sociais (PINHEIRO; BAZZO; SILVEIRA, 2007).

Dessa forma, os currículos com enfoque CTS objetivam preparar os estudantes para o exercício da cidadania, visto que a tríade CTS busca integrar o conhecimento científico com a tecnologia e o mundo social. Não se refere, portanto, apenas a junção de três letras com conceitos específicos, vai além. Pressupõe uma nova perspectiva sobre esses conceitos. Referem-se às relações recíprocas e abrangem a interação necessária entre esses três eixos (SANTOS; MORTIMER, 2002). Assim, sugere-se que os conteúdos a serem trabalhados, envolvam temas de interesse social, relacionando aspectos científicos e tecnológicos, que possibilitem ao estudante o desenvolvimento de sua criticidade e de atitudes responsáveis.

Sequências de ensino e aprendizagem com foco em ciência, tecnologia e sociedade (CTS)

Segundo Méheut (2005), as Sequências de Ensino e Aprendizagem (SEA - originalmente teaching learning sequences - TLS) consistem em um conjunto de atividades que tem como objetivos: auxiliar os estudantes no processo de compreensão do conhecimento científico e planejar o ensino de um conteúdo, de modo a maximizar as potencialidades das diversas estratégias didáticas dentro de uma rede interligada de ações. Para isso, Méheut e Psillos (2004) propõe um modelo, Modelo do Losango Didático (figura 1), para construção e validação de uma SEA, definindo quatro componentes básicos: o professor, os estudantes, o conhecimento científico e o mundo material, interligados a partir de duas dimensões: epistêmica e pedagógica. Na dimensão epistêmica, considera-se a relação 
existente entre o mundo real e o conhecimento científico, compreendendo uma ciência à vista de um mundo holístico, heterogêneo e histórico-social. Está relacionada aos conteúdos a serem apreendidos, a origem do conhecimento científico e sua relação com o mundo material. Já na dimensão pedagógica, são pensados aspectos relativos ao papel do professor e do estudante, às relações dialógicas e às interações que se estabelecem entre esses no âmbito da sala de aula.

Figura 1 - Modelo do losango didático

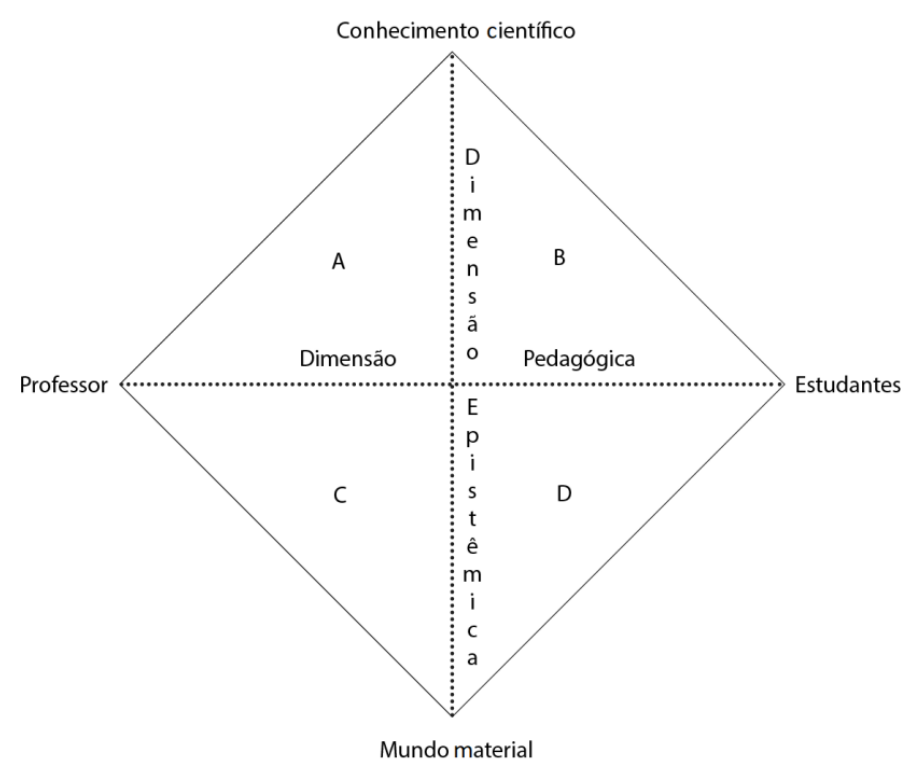

Fonte: Adaptado de Méheut e Psillos (2004).

Dentre os quadrantes (A, B, C e D) apresentados na figura 1, cabe aqui um destaque ao quadrante "C". Neste, em que os eixos pedagógico e epistêmico mostram a relação implícita entre o professor e o mundo material, cabe uma discussão acerca da confusão entre os termos cotidiano e contextualização. De acordo com Wartha, Silva e Bejarano (2013), um ensino de ciências com enfoque conceitual, que apenas "pincela" aspectos do cotidiano com o intuito de disfarçar a abstração excessiva de um ensino puramente conceitual, deixa à margem os reais problemas sociais. Como forma de tentar estabelecer relações mais próximas entre contexto e conceito, Silva e Marcondes (2015), embasados nos estudos e no modelo criado por Aikenhead (1990 apud SANTOS; SCHNETZLER, 2010), apresentam um novo modelo (Figura 2) capaz de orientar professores no planejamento de aulas e/ou no desenvolvimento de materiais didáticos contextualizados, com vistas à discussão de questões envolvendo a tríade CTS. 
Figura 2 - Modelo para planejamento e desenvolvimento de materiais didáticos pautados na perspectiva CTS

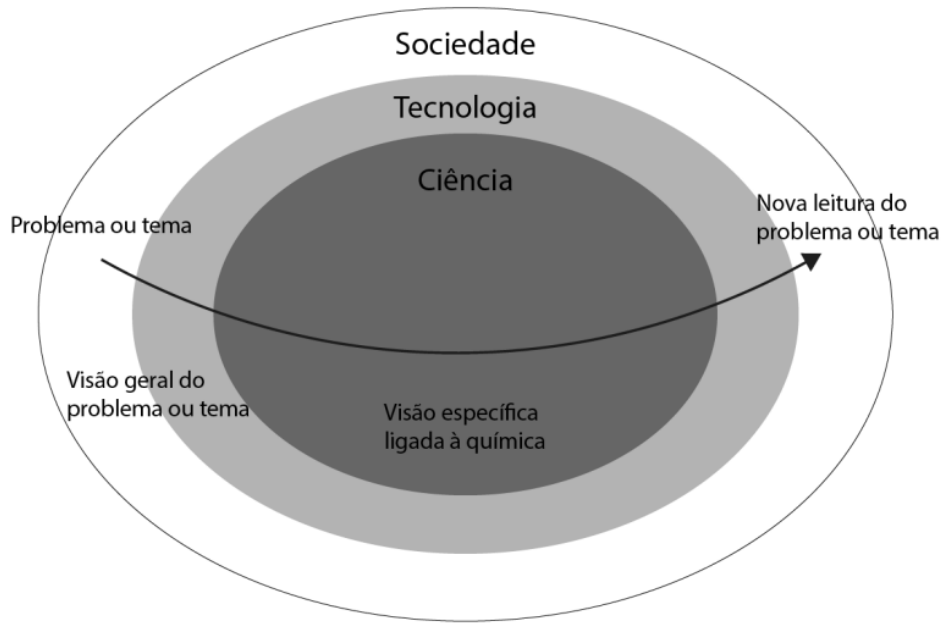

Fonte: Silva e Marcondes (2015, p. 68).

Sendo assim, ao elaborar a SEA, aqui apresentada, pautada na perspectiva CTS, tomamos como referência os quatro componentes propostos por Méheut (2005), assim como as suas dimensões, e propusemos atividades que possibilitassem a construção de significados para os conceitos científicos e interações discursivas mais significativas entre estudantes e professores, articulando esses conceitos científicos a contextos tecnológicos e sociais.

\section{Ensino de radioatividade}

Mesmo sendo tão presente nos dias atuais, a história das radiações iniciou em 1895, por Wilhelm Conrad Rontgen, ao observar que uma placa de vidro pintada com platinocianeto de bário se tornava luminescente quando em um tubo de raios catódicos, era aplicada uma diferença de potencial entre os eletrodos, embora o tubo estivesse envolto em papel opaco. Esse experimento levou Roengten à descoberta dos chamados "raios X” (OKUNO, 2018).

Pesquisas têm revelado que as dificuldades encontradas no ensino de radioatividade estão associadas principalmente a abstração desse conteúdo, visto que se trata de um fenômeno que ocorre a nível sub-microscópico, compreende desde a atomística, evolução dos modelos atômicos, até a física nuclear, transformações como fissão, fusão e decaimento radioativo (TEKIN; NAKIBOGLU, 2006; PELICHO, 2009). Além disso, devido ao conhecimento de senso comum, os estudantes costumam confundir irradiação com contaminação radioativa, que objetos irradiados tornam-se fontes de radiação e que a radiação causa mutação e é em todos os casos prejudicial ao homem. 
Sendo assim, propõe-se com a aplicação da SEA, aqui apresentada, pautada na perspectiva CTS, amenizar essas dificuldades e desmistificar alguns conceitos, buscando relacionar o conteúdo de radioatividade com os aspectos sociais e tecnológicos, para que assim os estudantes sejam estimulados a refletir sobre o que está sendo ensinado e possuir condições de formular seus próprios pensamentos e reflexões acerca de determinado conteúdo.

\section{Metodologia}

Esta investigação é um estudo de natureza qualitativa visto que, segundo Oliveira (2003), é uma tentativa de se explicar em profundidade o significado e características dos dados obtidos sem mensuração quantitativa de características ou comportamento.

Além disso, representa um recorte de uma dissertação, desenvolvida em três fases ou etapas distintas e complementares: [1] Fase exploratória: revisão bibliográfica de artigos científicos publicados na revista Química Nova na Escola - QNEsc sobre a perspectiva CTS e o conteúdo de radioatividade, no recorte temporal de 2009 a 2019. [2] Elaboração de uma Sequência de Ensino e Aprendizagem (SEA) pautada na perspectiva CTS, sobre o conteúdo de radioatividade, tendo como tema estruturador "radioatividade: riscos e benefícios". [3] Aplicação da SEA em uma turma inclusiva, do $3^{\circ}$ ano do Ensino Médio de uma escola da rede privada de ensino da cidade do Recife, obedecendo aos procedimentos éticos estabelecidos para a pesquisa científica em Ciências Humanas. Com relação ao perfil da turma, eram estudantes de classe comum e estudantes com deficiências motoras e psíquicas, envolvendo surdez, autismo, Transtorno do Déficit de Atenção (TDA), Transtorno do Déficit de Atenção com Hiperatividade (TDAH) e Síndrome de Irlen (S.I.). Para o presente trabalho teremos como foco a fase de elaboração da SEA.

Com base na revisão bibliográfica realizada na fase exploratória foi possível compreender o tema sob diversos ângulos e obter uma ideia mais ampla sobre o estado atual das publicações sobre a perspectiva CTS e a radioatividade, e, sobretudo, as lacunas, de modo a perceber como essa investigação poderia contribuir para a construção desse diálogo na área de ensino de química. A partir desse levantamento e de outras leituras, foram tecidas considerações e elaborada uma Sequência de Ensino e Aprendizagem (SEA) pautada na perspectiva CTS, sobre o conteúdo de radioatividade, tendo como tema estruturador "radioatividade: riscos e benefícios" e produzidos uma série de materiais instrucionais, com a finalidade de oferecer aos estudantes instrumentos que possam desenvolver suas múltiplas capacidades. Alguns resultados que serão apresentados e discutidos nesse artigo são referentes à etapa [3]. 
Todos os dados foram coletados por meio de vídeo-gravação, a qual foi transcrita e posteriormente analisada. A análise em si levou em consideração os pressupostos da análise de conteúdo de Bardin (2016), cujo objetivo é relatar e interpretar o conteúdo existente em qualquer tipo de documento, seguindo então as seguintes etapas: pré-análise; exploração do material coletado; tratamento dos resultados, interpretação e inferência.

A pré-análise contou com uma leitura flutuante, a partir da qual foi estabelecido um contato inicial com os posicionamentos apresentados pelos estudantes nas discussões, buscando formar as primeiras impressões sobre os mesmos. Novas leituras buscaram identificar, a partir da demarcação de algumas falas, que indícios nos permitiriam fazer associações com o conteúdo de Radioatividade e as relações CTS.

Essas demarcações nos permitiram chegar às unidades de registro ou análise, que, segundo Bardin (2016), "é a unidade de significação a codificar e corresponde ao segmento de conteúdo a considerar como unidade base, visando a categorização e análise frequencial”. Todas as unidades de registro foram submetidas à etapa de codificação, visando seu agrupamento em categorias, possibilitando a compreensão do real significado daquelas unidades de registro, para que se pudesse, ao final, inferir os reais sentidos que elas expressam e, no seu conjunto, quais as ideias centrais das falas analisadas.

Vale salientar que para a análise realizada, foram seguidas as regras definidas por Bardin (2016), com relação à exaustividade, exclusividade, representatividade e pertinência. Além disso, com o intuito de identificar os atores sociais da pesquisa e manter o anonimato, foi solicitado que criassem um nome radioativo próprio, que os deixassem mais pertencentes à pesquisa. Sendo assim, irei me referir aos atores sociais da pesquisa pelo seu nome radioativo.

\section{Resultados e discussão}

O quadro 1 mostra os aspectos utilizados para a elaboração da SEA, sinalizando as atividades desenvolvidas e os objetivos propostos para cada uma das atividades planejadas. 


\section{Dialogia}

MONTEIRO, Maria Daiane da Silva; SILVA, Suely Alves da. Sequência de Ensino e Aprendizagem sobre radioatividade pautada na perspectiva Ciência-Tecnologia-Sociedade (CTS)

Quadro 1 - Sistematização da SEA

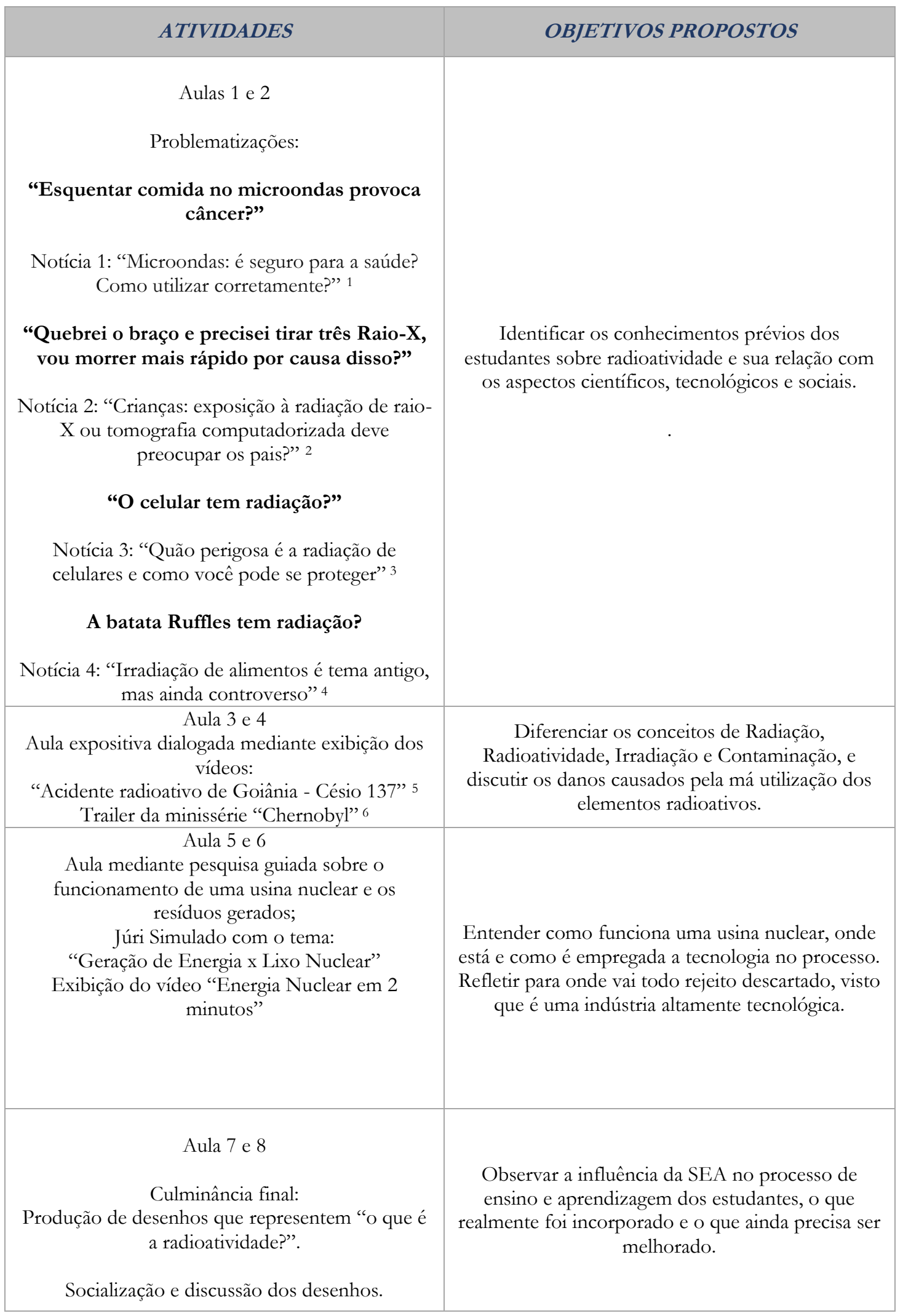

Fonte: Própria. 
Como mostrado no quadro, as aulas 3 e 4 objetivaram diferenciar os conceitos de Radiação, Radioatividade, Irradiação e Contaminação, e discutir os danos causados pela má utilização dos elementos radioativos. Para isso, essas aulas contaram com a exibição do documentário intitulado: “Acidente radioativo de Goiânia - Césio 137” e do trailer da minissérie "Chernobyl” do Home Box Office (HBO).

Após as exibições, foram colocadas, pela professora, algumas questões problematizadoras, de modo a gerar contrapontos, comparar os dois acidentes nucleares (um local e um global) e, principalmente, desmistificar os termos “Radiação, Radioatividade, Contaminação e Irradiação". A primeira delas foi "Há diferença entre radiação e radioatividade?". Vários foram os pontos de vista trazidos, entretanto de acordo com Ciscato e Pereira (2012) e Okuno e Yoshimura (2010) a radiação é entendida como a propagação de energia no espaço, com velocidade específica, podendo ser irradiada em todas as direções e classificada como eletromagnética ou corpuscular. E sobre radioatividade, Ciscato e Pereira (2012) acreditam que ela pode ser compreendida como o estudo das reações que ocorrem no interior do átomo, no núcleo atômico, as chamadas de reações nucleares. Essas reações ocorrem devido à instabilidade dos elementos químicos (os elementos radioativos), que por sua vez tendem a emitir partículas e/ou energia para alcançar a estabilidade. Sendo assim, tomaremos essas definições de radiação e radioatividade como parâmetros para nossas análises.

De modo a tornar a discussão mais interessante a professora faz um segundo questionamento “Há diferença entre contaminação radioativa e irradiação?”. Segundo Rodrigues Jr. (2007), é de extrema importância enfatizar a diferença entre contaminação radioativa e irradiação, pois, muitas vezes, esses conceitos são tidos como sinônimos. Neste sentido, adotaremos como conceitos de referência para análise dos dados o que diz Couto e Santiago (2010). Segundo esses autores, a irradiação é a exposição de um objeto ou corpo à radiação, o que pode ocorrer a alguma distância, sem necessidade de um contato direto com a fonte radioativa. Já, a contaminação radioativa caracteriza-se pela presença indesejável e acidental de material radiativo em determinado local, onde não deveria estar.

Objetivando perceber se os estudantes conseguem aplicar os conceitos vistos, a professora finaliza indagando "Quando precisamos 'tirar' Raio-X, estamos sendo irradiados ou contaminados?".

Nesse processo de discussão, emergiram três categorias empíricas, as quais correspondem às nossas categorias teóricas, visto que foram elaboradas questões e, por esse motivo, já era de se esperar as concepções dos estudantes sobre essas questões nas respostas dadas. Entretanto, a 


\section{Dialogia}

MONTEIRO, Maria Daiane da Silva; SILVA, Suely Alves da. Sequência de Ensino e Aprendizagem sobre radioatividade pautada na perspectiva Ciência-Tecnologia-Sociedade (CTS)

diversidade de respostas nos forneceu cinco subcategorias, as quais são apresentadas no quadro 2, juntamente com as categorias e as unidades de contexto. Cabe destacar que a seleção das falas decorreu da participação dos estudantes na discussão.

Quadro 2 - Categorias, unidades de contexto e subcategorias das falas dos estudantes no processo de discussão

\begin{tabular}{|c|c|c|}
\hline Categorias & Unidades de contexto & Subcategoria \\
\hline $\begin{array}{c}\text { Diferença entre } \\
\text { Radioatividade } \\
\text { e Radiação }\end{array}$ & $\begin{array}{l}\text { Fala 1: "radioatividade e radiação é quase a mesma coisa, eu acho." } \\
\text { (Prótinho) } \\
\begin{array}{r}\text { Fala 2: "Eu acho que a radiação tá dentro da radioatividade mas a } \\
\text { radioatividade não é radiação" (Ativi) }\end{array} \\
\text { Fala 3: "eu acho que radioatividade é o assunto geral que engloba } \\
\text { tudo isso, porém radiação é ação do elemento, o que o elemento faz, } \\
\text { ele emite radiação” (Prótinho) } \\
\text { Fala 4: "não necessariamente a radiação é radioatividade" (Marie Curie) } \\
\text { Fala 5: "eu n sei, eu não consigo definir radioatividade separado } \\
\text { assim. para mim é como se a radioatividade fosse um núcleo e dentro } \\
\text { da radioatividade tivessem outras coisas, tipo a radiação, etc...” (Ativr) }\end{array}$ & $\begin{array}{l}\text { Não há } \\
\text { diferença }\end{array}$ \\
\hline $\begin{array}{l}\text { Diferença entre } \\
\text { irradiação e } \\
\text { contaminação }\end{array}$ & $\begin{array}{l}\text { Fala 1: irradiação é ação de emitir radiação (Prótinho) } \\
\text { Fala 2: "irradiar é como se você tivesse um alimento e precisasse } \\
\text { exportar. Você precisa que ele dure muito tempo porque demora para } \\
\text { você colocar no avião e tudo mais. Não é que o alimento esteja } \\
\text { radioativo é como se passasse e saísse por ele uma quantidade de } \\
\text { radiação. Não absorve a radiação. Ele não fica radioativo" (Césio-137) } \\
\text { Fala 3: "então se ele absorve isso aí seria contaminação" (Prótinho) } \\
\text { Fala 4: “irradiação seria a emissão de radiação em alguma coisa" (Beta) } \\
\text { Fala 5: "a gente viu na notícia do microondas que estávamos } \\
\text { discutindo ontem, que ele irradia o alimento, ele agita as moléculas de } \\
\text { água do alimento mas sem contaminá-lo, ou seja, ele não absorve } \\
\text { radiação" (Ativi) }\end{array}$ & Há diferença \\
\hline
\end{tabular}




\begin{tabular}{|c|c|c|}
\hline \multirow[t]{2}{*}{$\begin{array}{c}\text { Aplicação dos } \\
\text { conceitos de } \\
\text { irradiação e } \\
\text { contaminação } \\
\text { no Raio-x. }\end{array}$} & $\begin{array}{l}\text { Fala 1: “estamos recebendo radiação e consequentemente sendo } \\
\text { irradiado para emitir a imagem” (Beta) } \\
\text { Fala 5: “eu tenho certeza agora que quando você toma raio-x você é } \\
\text { irradiado porque os médicos ficam fora e eles tem que ficar com } \\
\text { aquela proteção porque eles passam muito tempo trabalhando com a } \\
\text { radiação, não é prejudicial para a gente porque só passamos o tempo } \\
\text { do exame” (Beta) } \\
\text { Fala 6: “eu sigo um YouTuber no Instagram ele foi para Chernobyl. } \\
\text { Ele fala no vídeo que tava recebendo radiação porém ele não poderia } \\
\text { tocar em nada porque aí ele não iria conseguir sair de lá eles estariam } \\
\text { com nível muito alto que é a contaminação” (Beta) }\end{array}$ & $\begin{array}{l}\text { Entendem } \\
\text { como } \\
\text { irradiados }\end{array}$ \\
\hline & $\begin{array}{c}\text { Fala 3: "eu pensaria em contaminação radioativa quando a gente eleva } \\
\text { os níveis de radiação acima dos aceitáveis. Porque ao pensar em } \\
\text { radiação lembramos do Sol, nós recebemos radiação até do Sol mas } \\
\text { pode chegar a ser prejudicial você pode receber radiação mas quando } \\
\text { você ultrapassa aí sim e você é contaminado” (Ativi) } \\
\text { Fala 4: “ eu pensei agora sobre o porquê as pessoas ficam cobertas, } \\
\text { porque quando quando você está acompanhando a pessoa não pode } \\
\text { entrar na sala de raio-x, nem grávida, então seria contaminação” } \\
\text { (Elemento X) }\end{array}$ & $\begin{array}{c}\text { Entendem } \\
\text { como } \\
\text { contaminados }\end{array}$ \\
\hline
\end{tabular}

Fonte: Própria.

Com base nos resultados obtidos, inicialmente, há uma confusão entre os conceitos de Radiação e Radioatividade. Entretanto, percebemos uma evolução nos posicionamentos dos estudantes assim que pontos de vista distintos foram levantados, o que pode ser visto, por exemplo, nas falas de Prótinho. No início o estudante acredita que não há diferença entre radiação e radioatividade, mas logo após o posicionamento da estudante Ativi, reorganiza suas concepções iniciais, mostrando que há diferença ao afirmar que "radiação é ação do elemento, o que o elemento faz, ele emite radiação". Segundo Anastasiou e Alves (2012), a aula dialogada tem esse papel, de favorecer uma análise crítica e, com isso, produzir novos conhecimentos, considerando a participação ativa dos estudantes e seus conhecimentos prévios como ponto de partida.

Quando os estudantes são questionados sobre a diferença entre Irradiação e Contaminação radioativa, todos que se posicionaram a respeito, compreendem que existe diferença entre esses dois termos e ainda conceituam irradiação, de um modo geral, como sendo "a ação de emitir radiação (Prótinho)" e entendem que a contaminação radioativa acontece quando a radiação é absorvida, "então se ele absorve isso aí seria contaminação (Prótinho)", o que condiz com as concepções de Couto e Santiago (2010). A estudante Ativi mostra a diferença entre esses dois conceitos através de uma aplicação cotidiana, que foi discutida nas aulas 1 e 2, o microondas. A mesma afirma que "o microondas irradia o alimento [...] sem contaminar [...] ou seja ele não absorve radiação”, o que também confere com as ideias de Couto e Santiago (2010) sobre contaminação radioativa. 
Diante disso, conseguimos perceber indícios de um ensino com enfoque CTS, visto que alguns estudantes já começam a estabelecer, mesmo que de forma tímida, relações entre o conhecimento científico, a tecnologia e os aspectos sociais. Isso fica mais evidente nas respostas das estudantes Ativi e Césio-137, essa última ainda trazendo em sua fala, aspectos econômicos, como a exportação. Com isso, compreendemos o quão significativo é trabalhar os conteúdos químicos dentro de uma perspectiva de ensino que possibilite a discussão de questões que normalmente não são abordadas nas aulas de química, introduzindo conceitos e construindo-os, em essência, de forma mais significativa.

Por fim, quando os estudantes são estimulados a aplicar os conhecimentos adquiridos, dos que se posicionaram, alguns ainda não conseguiram relacionar adequadamente os conceitos às aplicações. É neste sentido que a inserção de abordagens e estratégias didáticas que retratem as dificuldades dos estudantes com relação à compreensão de conceitos relacionados à radioatividade e que levem em consideração o desenvolvimento científico, tecnológico e as questões sociais e ambientais intrínsecos ao estudo dessa temática, devem ser consideradas, visando desenvolver o senso crítico dos estudantes e capacitar cidadãos para julgar as implicações do desenvolvimento científico-tecnológico (SILVA; MARCONDES, 2015).

Ao observar as falas dos estudantes, apenas um deles (Beta) considera que somos irradiados ao 'tirarmos' raio-x. Em seu posicionamento o estudante além de associar o conceito químico à aplicação, traz argumentos que nos permite inferir que se estabeleceu uma relação CTS. O estudante entende é a partir da irradiação que a imagem é emitida, menciona o acidente nuclear de Chernobyl, a tecnologia é vista por ele na utilização do Raio-x na medicina, e ainda menciona fontes alternativas de obtenção de conhecimentos, como as mídias sociais, aproximando o conhecimento científico da sua realidade, seu contexto.

Nas falas dos estudantes que afirmam ser contaminação, é perceptível uma dificuldade em relacionar o conceito à aplicação, os mesmos demonstram entender o papel da ciência, da tecnologia e da sociedade, e que interrelações entre esses três eixos acontecem, porém o conceito de contaminação radioativa é mal interpretado. Neste sentido, Bocheco (2011) acredita que a maior preocupação em trabalhar com abordagens que contemple as relações CTS, está no sentido de estabelecer um equilíbrio entre os conteúdos disciplinares e as discussões CTS, para que não se privilegiei um eixo em detrimento de outro. 
MONTEIRO, Maria Daiane da Silva; SILVA, Suely Alves da. Sequência de ensino e aprendizagem sobre radioatividade pautada na perspectiva Ciência-Tecnologia-Sociedade (CTS)

\section{Considerações finais}

Diante do exposto, consideramos que a introdução de estratégias didáticas nas quais a contextualização dos conteúdos químicos transcendam exemplos cotidianos simples e estenda a visão de mundo dos estudantes para as grandes questões sociais e ambientais que os rodeiam, são fundamentais. Principalmente, na abordagem de conteúdos que apresentam abstração e dualidade, como a radioatividade. É nessa perspectiva, de contribuir com discussões dessa natureza, que propostas pautadas na perspectiva CTS vêm sendo amplamente divulgadas na pesquisa e no ensino de química. Nossa SEA com foco na discussão sobre os riscos e benefícios da radioatividade na sociedade é uma entre as muitas propostas que podem contribuir para a aprendizagem de conceitos científicos e proporcionar um repensar e um reavaliar a visão dos estudantes de que a radioatividade causa apenas mortes e destruição.

Portanto, espera-se que esse trabalho possa apoiar discussões sobre as contribuições da perspectiva CTS no âmbito da sala de aula e na promoção de uma aprendizagem crítica dos estudantes, em que a química adquire significado no âmbito dos problemas sociais e das relações humanas, científicas e tecnológicas.

${ }_{1}^{1}$ Disponível em: https://www.tuasaude.com/micro-ondas-e-a-saude/ Acesso em jun. 2020.

2 Disponível em: https://www.clickguarulhos.com.br/2016/08/07/criancas-exposicao-a-radiacao-de-raio-x-outomografia-computadorizada-deve-preocupar-os-pais/ Acesso em jun. 2020.

${ }^{3}$ Disponível em: http://g1.globo.com/bemestar/noticia/2016/11/quao-perigosa-e-a-radiacao-de-celulares-e-comovoce-pode-se-proteger.html Acesso em jun. 2020.

${ }^{4}$ Disponível em: http://www.labjor.unicamp.br/midiaciencia/article.php3?id_article=244> Acesso em jun. 2020.

${ }^{5}$ Disponível em: https://www.youtube.com/watch?v=MfshO3PvlYs\&t=2s. Acesso em jun. 2020.

${ }^{6}$ Disponível em: https://www.youtube.com/watch?v=jQO2EhzG-uU. Acesso em jun. 2020.

\section{Referências}

ANASTASIOU, L. G. C.; ALVES, L. P. Processo de ensinagem na universidade: pressupostos para estratégias de trabalho em aula. 10. ed. Joinville, SC: Univille, 2012.

BARDIN, Laurence. Análise de conteúdo. São Paulo: Edições 70, 2016.

BOCHECO, Otávio. Parâmetros para a abordagem de evento no enfoque CTS. 2011. Dissertação (Mestrado em Educação Científica e Tecnológica) - Universidade Federal de Santa Catarina, Florianópolis, 2011. Disponível em: https://repositorio.ufsc.br/bitstream/handle/123456789/95281/294999.pdf?sequence=1\&isAll owed=y. Acesso em: 21 mai. 2020.

BRASIL. Base Nacional Comum Curricular: Ensino Médio. Brasília: Ministério da Educação/Secretaria de Educação, 2018. 


\section{Dialogia}

MONTEIRO, Maria Daiane da Silva; SILVA, Suely Alves da. Sequência de Ensino e Aprendizagem sobre radioatividade pautada na perspectiva Ciência-Tecnologia-Sociedade (CTS)

BRASIL. Lei de Diretrizes e Bases da Educação Brasileira. Lei ño 9.394/96, de 20 de dezembro de 1996.

BRASIL. Parâmetros Curriculares Nacionais do Ensino Médio. Brasília: MEC/SESu, 1999.

CISCATO, C. A. M; PEREIRA, L.F. Planeta Quimica. São Paulo: Editora Ática, 2012.

COUTO, R. R., SANTIAGO, A. J. Radioatividade e Irradiação de Alimentos. Revista Ciências Exatas e Naturais, v.12 , n. 2, 2010. Disponível em:

https://pdfs.semanticscholar.org/abaf/8bb8e243a6db02dd8e75477bf14685f74c0c.pdf. Acesso em: 21 mai. 2020.

MÉHEUT, M.; PSILLOS, D. Teaching-learning sequences: aims and tools for science education research. International Journal of Science Education, London, v. 26, n. 5, p. 515-535, 2004.

MÉHEUT, Martine. Teaching-learning sequences tools for learning and/or research. In: BOERSMA, K. et al. (Ed.). Research and quality of science education. Dordrecht: Springer, p. 195-207, 2005.

OKUNO, E; YOSHIMURA, E. Física das Radiações. 1. ed. São Paulo: Oficina de Textos, 2010.

OKUNO, Emico. RADLAÇAO: EFEITOS, RISCOS E BENEFICIOS. 1. ed. São Paulo: Oficina de Textos, 2018.

OLIVEIRA, Maria Marly de. Como Faz̨er Projetos, Relatórios, Monografias, Dissertações e Teses. Recife: Edições Bagaço, 2003. Cap. 3, p. 53-74.

OLIVEIRA, Vera Barros de. Jogos de regras e resoluções de problemas. 2. ed. Vozes, 2004.

PELICHO, Aléscio Fachim. Irradiando Conhecimento: uma abordagem da radioatividade para o Ensino Médio. In: CONGRESSO PARANAENSE DE EDUCAÇÃO EM QUÍMICA, 1., 2009, Londrina. Anais eletrônicos... Londrina, 2009. Disponível em:

http://www.uel.br/eventos/cpequi/Completospagina/18154845420090611.pdf. Acesso em: 21 mai. 2020.

PINHEIRO, Nilcéia Aparecida Maciel. Educação Crítico-Reflexiva para um Ensino Médio CientíficoTecnológico: a contribuição do enfoque CTS para o ensino-aprendizagem do conhecimento matemático. 2005. Tese (Doutorado em Educação Cientifica e Tecnológica) - Universidade Federal de Santa Catarina, Florianópolis, 2005. Disponível em:

https://repositorio.ufsc.br/bitstream/handle/123456789/101921/222011.pdf? sequence=1\&isAl lowed $=$ y. Acesso em: 21 mai. 2020.

PINHEIRO, N. A. M.; BAZZO, W. A; SILVEIRA, R. M. C. F. Ciência, Tecnologia e Sociedade: a relevância do enfoque CTS para o contexto do ensino médio. Ciência \&Educação, v. 13, n. 1, p. 71 84, 2007. Disponível em: https://www.scielo.br/pdf/ciedu/v13n1/v13n1a05.pdf. Acesso em: 21 mai. 2020.

RODRIGUES JR., Ary de Araújo. O que é irradiação? E contaminação radioativa? Vamos esclarecer? Física na Escola, v.8, n. 2, 2007. Disponível em: 


\section{Dialogia}

MONTEIRO, Maria Daiane da Silva; SILVA, Suely Alves da. Sequência de ensino e aprendizagem sobre radioatividade pautada na perspectiva Ciência-Tecnologia-Sociedade (CTS)

https://www.researchgate.net/publication/255483343_O_que_e_irradiacao_E_contaminacao_r adioativa_Vamos_esclarecer. Acesso em: 21 mai. 2020.

SANTOS, W. L. P.; MORTIMER, E. F. Uma análise de pressupostos teóricos da abordagem CT-S (Ciência-Tecnologia-Sociedade) no contexto da educação brasileira. Ensaio - Pesquisa em Educação em Ciências, v. 2, n. 2, p. 1-23, 2002. Disponível em:

https://www.scielo.br/pdf/epec/v2n2/1983-2117-epec-2-02-00110.pdf. Acesso em: 21 mai. 2020.

SANTOS, W. L. P.; SCHNETZLER, R. P. Educaşão em Química: compromisso com a cidadania. $4^{a}$ ed. Ijuí: Ed. Unijuí, 2010.

SCHNETZLER, Roseli Pacheco. A pesquisa em Ensino de Química no Brasil: conquistas e perspectivas. Quimica Nova, v. 25, supl. 1, p. 14-24, 2002. Disponível em:

https://www.researchgate.net/publication/26352581_A_pesquisa_em_ensino_de_quimica_no_ Brasil_conquistas_e_perspectivas. Acesso em: 21 mai. 2020.

SILVA, E. L.; MARCONDES, M. E. R. Materiais didáticos elaborados por professores de química na perspectiva CTS: uma análise das unidades produzidas e das reflexões dos autores. Ciência \& Educação, Bauru, v. 21, n. 1, p. 65-83, 2015. Disponível em: https://www.scielo.br/pdf/ciedu/v21n1/1516-7313-ciedu-21-01-0065.pdf. Acesso em: 21 mai. 2020.

TEKIN, B. B.; NAKIBOGLU, C. Identifying studente's misconceptions about nuclear chemistry. A study of Turkish high school students. Journal of Chemical Education, 83, n. 11 p. 1712, 2006.

VAZ, C. R.; FAGUNDES, A. B.; PINHEIRO, N. A. M. O surgimento da ciência, tecnologia e sociedade (CTS) na educação: uma revisão. In: Simpósio Nacional de Ensino de Ciência e Tecnologia, 1., 2009, Curitiba. Anais eletrônicos... Curitiba, 2009. Disponível em: http://www.sinect.com.br/anais2009/artigos/1\%20CTS/CTS_Artigo8.pdf. Acesso em: 21 mai. 2020.

WARTHA, E. J.; SILVA, E. L.; BEJARANO, N. R. R. Cotidiano e Contextualização no Ensino de Química. Quimica Nova na Escola, v. 35, nº 2, p. 84-91, 2013. Disponível em:

http://qnesc.sbq.org.br/online/qnesc35_2/04-CCD-151-12.pdf. Acesso em: 21 maio 2020.

Recebido em: 29 set. 2020/ Aprovado em: 01 dez. 2020

Cite como

(ABNT NBR 6023:2018)

MONTEIRO, Maria Daiane da Silva; SILVA, Suely Alves da. Sequência de ensino e aprendizagem sobre radioatividade pautada na perspectiva Ciência-Tecnologia-Sociedade (CTS). Dialogia, São Paulo, n. 36, p. 595-609, set./dez. 2020. Disponível em: https://doi.org/10.5585/dialogia.n36.18314.

\section{American Psychological Association (APA)}

Monteiro, M. D. S., \& Silva, S. A. (2020, set./dez.). Sequência de ensino e aprendizagem sobre radioatividade pautada na perspectiva Ciência-Tecnologia-Sociedade (CTS). Dialogia, São Paulo, 36, p. 595-609.

https://doi.org/10.5585/ dialogia.n36.18314. 